\title{
Educação, formação profissional docente e os paradigmas da ciência
}

\author{
Education, professional teacher \\ education and the paradigms of science
}

\author{
Ana Cristina Gipiela PIENTA ${ }^{1}$ \\ Danilene Donin BERTICELLI ${ }^{2}$ \\ Maria Dagmar da Rocha GASPAR ${ }^{3}$ \\ Marilda Aparecida BEHRENS ${ }^{4}$
}

RESUMO: O objetivo deste artigo é propor uma reflexão sobre os paradigmas da ciência e o desafio da educação. A educação vive diversas crises resultantes de tendências pedagógicas que historicamente permearam as práticas de ensino e aprendizagem. No texto, procuramos identificar as influências e manifestações dos paradigmas da ciência no pensamento e nas práticas pedagógicas. Relatamos a nítida presença do pensamento newtoniano - cartesiano influenciando as pedagogias conservadoras, conferindo ao trabalho pedagógico a função reprodutora do conhecimento, através de práticas fragmentadas e mecanicistas. Em seguida, propomos a superação desse modelo por meio da aliança entre paradigmas inovadores com características progressistas, fundamentadas no paradigma da produção do conhecimento. Mostramos que, aliando dimensões anteriormente dissociadas, como razão e emoção, é possível cumprir o compromisso com a formação do indivíduo sistêmico, a qual supera o modelo exclusivamente intelectual. Concluindo a reflexão, nos questionamos: o que está faltando para que o profissional da

\footnotetext{
${ }^{1}$ Especialista em Organização do Trabalho Pedagógico pela Universidade Federal do Paraná. Pedagoga da Gerência de Capacitação Profissional da Secretaria Municipal da Educação de Curitiba. Professora do Departamento de Planejamento e Administração Escolar da Universidade Federal do Paraná - UFPR. E-mail: anacgp@pop.com.br

${ }^{2}$ Graduada em Ciências - Habilitação em Matemática - pela Universidade Paranaense. Professora do Ensino Médio de Matemática e Física em Palotina. E-mail: berticelli@qinfonet.com.br

${ }^{3}$ Graduada em Enfermagem pela Universidade Federal do Piauí. Especialista em Infecção Hospitalar pela Pontifícia Universidade Católica do Paraná. Professora do curso de Enfermagem da Universidade Estadual de Ponta Grossa. Enfermeira do Hospital Santa Casa de Misericórdia, em Ponta Grossa. E-mail: mdagrocha@yahoo.com.br

${ }^{4}$ Doutora em Educação pela Pontifícia Universidade Católica de São Paulo. Professora do Programa de Mestrado em Educação da PUCPR. E mail: marilda.aparecida@pucpr.br
} 
educação esteja apto a atuar sem sofrer as conseqüências dessas mudanças? O que precisa ser feito para que sociedade e escola andem lado a lado na busca de uma formação que prepare o aluno para a ciência e para a paz? Apontamos, portanto, a necessidade de reflexão acerca das práticas de formação de professores e a urgência de ações coerentes com as propostas pelos paradigmas inovadores.

Palavras-chave: paradigmas, educação, mudança, conhecimento, formação de professores

ABSTRACT: The aim of this study is to propose a reflection on the paradigms of science and the challenge of education. Education is going through a crisis due to pedagogical tendencies that historically have permeated the practices of teaching and learning. In this study, we have tried to identify the influences and the expression of scientific paradigms on thought and pedagogical practices. We described the the newtonian-cartesian thinking which has influenced conservative ways of teaching, giving pedagogical work the function of reproducing knowledge through fragmented and mechanistic methods. Following that, we proposed surpassing this model by joining these innovating paradigms with progressive characteristics, based on the paradigm of producing knowledge. We tried to show that, linking dimensions that were previously dissociated, such as reason and emotion, it is possible to carry out the commitment of educating a sistemic individual who overcomes the exclusively intelectual model. Concluding the reflection, we ask ourselves: what is missing for the professional educator to be apt to act without suffering the consequences of these changes? What needs to be done for society and school to walk hand in hand in search of reflection on the practices of teacher education. Therefore, we point out the need of reflection on the practices of teacher education and the urgent need of coherent actions with the proposals given by innovating paradigms.

Key words: paradigms, education, change, knowledge, teacher education

\section{PARADIGMAS DA CIÊNCIA E O DESAFIODAEDUCAÇÃO}

As práticas pedagógicas adotadas ao longo dos anos nas instituições e sistemas educacionais sofreram mudanças necessárias de acordo com o período histórico em que estavam inseridas. Tais mudanças implicaram conseqüências que envolveram a sociedade, a cultura, o homem, a educação, o mundo em geral.

Fazendo um resgate na história da educação, nos deparamos com várias estratégias e modelos de ensinoaprendizagem que denotam a época em que se desenvolveram, constituindo paradigmas distintos, cada qual com características específicas no que diz respeito ao papel do professor, do 
aluno e da escola.

No contexto atual, nos defrontamos com dados, estatísticas e relatos da realidade que denotam as deficiências e equívocos presentes no diaa-dia de nossas escolas. Práticas pedagógicas que caracterizam o descompasso entre a educação e a atual sociedade globalizada necessitam de uma urgente reflexão.

A escola, como instituição que deve estar situada histórico, social, cultural e politicamente em seu tempo, necessita de práticas que superem a fragmentação e mecanização próprias do pensamento teórico de um tempo que já provou estar ultrapassado. A simples transmissão e reprodução de conhecimentos não atende às necessidades da sociedade atual, que, de forma progressiva, tem apresentado aos indivíduos desafios de naturezas diversas, exigindo raciocínio e ações que integram diversos campos de conhecimento.

A educação na sociedade moderna deve, ao mesmo tempo, usar os conhecimentos existentes e superar as dificuldades resultantes dos avanços tecnológicos e científicos, os quais em parte trouxeram grandes contribuições para a humanidade, mas também graves problemas para a natureza e para o homem.

Durante um longo período tivemos um modelo de educação marcado pelo paradigma newtoniano-cartesiano, que separava a razão da emoção, dando mais ênfase à primeira. Formava, assim, um ser humano insensível, pre- parado somente para a reprodução e para enfrentar o mundo-máquina:

A estrutura e a organização dos cursos concebidos com uma visão mecanicista, fragmentada, $e$ de maneira disciplinar, precisa ser superada, para possibilitar um avanço nas instituições de ensino. Também torna-se desafiadora a busca da superação das práticas pedagógicas autoritárias e conservadoras, que se preocupam em vencer os conteúdos, em manter a disciplina baseada no silêncio em sala de aula, mantendo o pensamento acrítico e ingênuo na transmissão dos conteúdos, e as metodologias reprodutivas. (BEHRENS, 2000, p.88)

Esse processo de divisão do conhecimento levou o homem a entrar em conflito com os próprios sentimentos. A separação entre emoção e razão provocou insegurança e o homem não desenvolveu valores necessários para uma vida saudável, como a espiritualidade, a solidariedade, a humildade, a paciência, o amor ao próximo. Para Behrens (2000), a exacerbação da competitividade na sociedade atual, somada às influências do racionalismo, vem empurrando o homem a uma constante e crescente crise pessoal, alimentada pela cobrança de "eficiência e eficácia em favor de um produto e de um capital", conduzindo a um processo de auto-destruição e violência generalizada.

Percebe-se uma preocupação com 
a produção, com o capital, com a necessidade de acompanhar o desenvolvimento tecnológico, como se isso fosse gerar algum benefício para o próprio homem. As pessoas esquecem que o que alimenta a vida são os valores agregados ao ser humano. Sobre essa situação, Weil afirma:

Nosso mundo está em crise, provocada por lacunas e falhas do paradigma reinante e suas extrapolações. A felicidade prome-tida pelas aplicações indiscri-minadas da ciência moderna sob forma de tecnologia está se transformando no seu contrário; de um lado, temos a falta elementar de alimento e confronto, que traz fome e miséria física ao Terceiro Mundo; do outro lado, temos a miséria psicológica que acompanha o excesso de alimento e confronto dos países desenvolvidos, onde crescem a solidão, a indiferença, a violência sob todas as suas formas; o conforto não trouxe a felicidade, qualquer que seja o regime politico reinante. (1991, p.17)

Nesse contexto, buscamos a superação de antigos paradigmas, que permearam a educação durante um longo período. Para tanto, precisamos entender o conceito de paradigmas para compreender a sua relação com o ensino.

Segundo Kuhn (1994, p.225), "paradigma refere-se a modelo, padrões, crenças e valores compartilha- dos que permitem a explicação de certos aspectos da realidade, partilhados pelos membros de uma comunidade científica". Assim, determinada comunidade ou sociedade conhecem, pensam e agem segundo a força de um paradigma vivido culturalmente durante um determinado período histórico.

A resistência quanto à superação dos paradigmas conservadores da educação tem apontado para uma crescente marginalização e exclusão de grande parcela da população, acentuando o processo de desigualdade social. O avanço tecnológico e científico alcançado pela sociedade globalizada, quando não democratizado, acaba servindo como instrumento de exclusão.

O grande desafio que os educadores vivenciam é superar esse modelo conservador, que consiste no ensino autoritário, mecânico e descontextualizado, em que professor e aluno ficam restritos à reprodução do conhecimento.

De acordo com Behrens (2003, p.103), o desafio do paradigma inovador é buscar a recuperação do sentido educador da escola, devendo optar por uma visão de totalidade que integra ensino e vida, levando alunos e professores a encontrarem caminhos intelectuais, emocionais e profissionais.

\section{PARADIGMASCONSERVADORES}

A mudança paradigmática gerada pelo pensamento newtoniano - 
cartesiano, a partir do século XVI, resulta na troca de "senhor" ao qual a sociedade estava submissa: ela liberta-se da hegemonia religiosa, para aprisionar-se à hegemonia da ciência. De acordo com Corazza (2004), o conhecimento continua neutro e iluminado, uma vez que a ciência o conduziria para os retos caminhos do bem, da verdade e da vida.

A ciência passa a ser o único instrumento de representação do saber, relegando a humanidade e todo seu conhecimento para segundo plano. $\mathrm{O}$ principal pressuposto desse paradigma, infelizmente presente até a atualidade nas mais diversas práticas pedagógicas, é o de que para compreender o complexo é necessário compreender cada parte constitutiva. Ele aponta, portanto, para, a divinização da fragmentação.

Além da fragmentação como instrumento legitimador necessário para a compreensão do todo complexo, o racionalismo científico, na constante busca da neutralidade, desumanizou o conhecimento, afastando a emoção da razão, o corpo da mente, a ciência da ética. Na educação, separou o sujeito do objeto, o educador do educando, o conteúdo da forma. Nesse contexto, subjetividade, sensibilidade e humanidade são características que ameaçam a neutralidade científica.

Influenciados pela teoria newtoniana - cartesiana, muitos professores ainda concebem seus conhecimentos e saberes acima de qualquer suspeita. Caracterizam-se como meros transmissores da neutralidade científica, a qual é inquestionável, imutável, dogmática, unívoca, universal.

A serviço da transmissão do conhecimento, identificamos, na prática pedagógica, modelos educativos assentados em paradigmas conservadores da Ciência, com o objetivo de reproduzir e repetir a produção científica com uma visão mecanicista. São eles: paradigma tradicional, paradigma escolanovista e paradigma tecnicista. É impossível determinarmos períodos históricos para cada um desses modelos pedagógicos, uma vez que eles não se sucedem linearmente. Inclusive, coexistem e se interpenetram, criando novos referenciais e influenciando novos comportamentos e posturas.

A Pedagogia Tradicional, fundamentada na reprodução do conhecimento, valoriza o ensino humanístico, buscando conduzir o aluno ao conhecimento das grandes realizações da humanidade. Conforme Libâneo:

(...) se caracteriza por acentuar o ensino humanístico tradicional de cultura geral, onde o aluno é educado para atingir pelo próprio esforço sua plena realização como pessoa. Toda a prática educativa é desvinculada do cotidiano do aluno e muito menos das realidades pessoais; as regras são impostas e existe o cultivo do exclusivamente intelectual. (1986, p.22)

$\mathrm{O}$ aluno é considerado um recep- 
tor passivo das informações. É o ouvinte, assimilador de conteúdos e informações que são ensinadas pelo professor. Não existe liberdade de diálogo, ele é treinado para reproduzir. E, quanto mais, melhor. Existe uma relação vertical entre professor e aluno. O professor é considerado o detentor do saber: impõe, disciplina e se mantém distante do aluno. Tem a função de informar e conduzir seus alunos para a repetição (memorização) de informações, com autonomia de expor e analisar os conteúdos. As aulas são previamente preparadas (artificiais) e expositivas; nelas, o professor faz demonstrações à classe e trabalha com exercícios de repetição. A aula é uma arte centrada no professor, que é a figura principal desse processo. A aprendizagem é garantida, principalmente, pela repetição.

Nesse modelo, a escola é, exclusivamente, o lugar onde se realiza a educação, onde se raciocina. É uma agência sistematizadora de uma cultura complexa, na qual aprender é considerado um ato cerimonial. O processo avaliativo busca a exatidão da reprodução da disciplina repassada em sala de aula; para isso, utilizam-se interrogatórios orais, exercícios de casa, provas escritas e trabalhos.

A pedagogia tradicional trabalha com uma pedagogia liberal, com o intuito de preparar o aluno moral e intelectualmente. Para Mizukami (1986, p.18):

A escola é o local da apropriação do conhecimento, por meio da transmissão de conteúdos e confrontação com modelos e demonstrações. A ênfase não é colocada no educando, mas na intervenção do professor, para que a aquisição do patrimônio cultural seja garantida. O individuo nada mais é do que um ser passivo, um receptáculo de conhecimentos escolhidos e elaborados por outros para que ele deles se aproprie.

Percebe-se que o paradigma tradicional não contribui para uma mudança social: ao contrário, o seu papel - que ainda persiste nas escolas é o de impedir todo o processo de mudança. Diante disso, a reflexão de Behrens (1996, p. 82) torna-se pertinente: "A primeira impressão que se tem ao percorrer os corredores das universidades, salvaguardando as exceções, é que o paradigma tradicional de ensino nunca abandonou a sala de aula".

Em tal paradigma, observa-se o professor expondo os conteúdos e os alunos em silêncio, copiando receitas e modelos propostos. Com alguma habilidade, os alunos conseguem fazer questionamentos sobre os conteúdos, mas nem sempre encontram respostas que venham estabelecer um significado para a sua formação.

O Paradigma Escolanovista surge nas décadas de 20 e 30 no Brasil, como um movimento crítico à pedagogia tradicional. As informações de um novo tipo de escola - que surgiu na Europa e nos Estados Unidos, com 
as características de liberdade, obrigatoriedade e gratuidade no ensino - despertaram a atenção de educadores brasileiros, especialmente Anísio Teixeira, o qual lutava pela democratização do ensino.

Vários teóricos, como Dewey, Montessori, Decroly e Piaget, defendiam a democratização e socialização do ensino, com escolas para todos, desencadeando um movimento de reação à pedagogia tradicional. Eles baseavam-se nos fundamentos da biologia e da psicologia, dando ênfase ao indivíduo.

O aluno assume um papel mais liberal na abordagem escolanovista: é um ser único e livre, que busca a autorealização. É importante ressaltar que ele é considerado como um projeto permanente e inacabado, ou seja, organismo em processo de integração. Seus sentimentos e capacidades têm valor considerável e percebe-se uma preocupação com a postura, algo que não existia no ensino tradicional. Com isso, o professor não apenas transmite conteúdos, mas dá assistência ao aluno, sendo um facilitador da aprendizagem. Existe uma relação mais amigável entre ele e os alunos. O professor cria situações para que o aluno aprenda e desenvolva seu próprio repertório, considerando-o como ele é.

As aulas são centradas no aluno, que tem liberdade de criticar; promovem-se todos os tipos de recursos que estimulem a sua curiosidade. A escola é formadora de atitudes, possibilita a autonomia do educando, respeitan- do suas individualidades. É importante fazê-lo perceber que é capaz de atingir suas metas pessoais.

Para Luckesi (apud NIETSCHE, 1998, p.48), a "pedagogia escolanovista é centrada nos sentimentos, na espontaneidade da produção do conhecimento e no educando com suas diferenças individuais". A escola deve promover experiências que permitam ao aluno educar-se num processo ativo de construção e reconstrução do conhecimento, num processo de interação entre as estruturas cognitivas do indivíduo e as relações com o ambiente.

Vale ressaltar que a Escola Nova também não contemplou todo sistema educacional, pois foi incorporada apenas pelas escolas bem equipadas, destinadas à elite burguesa. $\mathrm{O}$ fato evidencia a desvinculação existente entre a Escola Nova e a realidade social, como destaca Leão:

A Escola Nova, apesar do princípio de que a ação educativa deve estar intimamente ligada à vida, aos interesses e necessidades do aluno a partir da sua realidade, está também, como a Escola Tradicional, desvinculada do contexto sócio-econômico-político e $e ́$, portanto considerada uma escola não crítica, uma escola que não contribui para uma mudança significativa na sociedade, uma vez que omite a realidade social, contribuindo desta forma para perpetuação da estrutura social vigente. (apud NIETSCHE, 
1998,p.134)

Ao final do século XX, surge a Pedagogia Tecnicista, fundamentada no Positivismo, inspirada nos princípios de racionalidade, eficiência, produtividade e nos pressupostos da neutralidade científica.

Aparece numa época de grande avanço do sistema industrial, o qual estava ligado à questão da automação e da divisão do trabalho. O elemento principal da abordagem tecnicista não é o professor nem o aluno, mas a organização racional dos meios. O planejamento e o controle asseguram a produtividade do processo. Nesse modelo, como destaca Behrens (2003, p.51), "ao separar corpo e mente, a ciência transfere para a educação um sistema fechado, compartilhado e dividido, e o ensino recai na técnica pela técnica".

$\mathrm{Na}$ abordagem tecnicista a aluno é considerado um produto do meio em que está inserido, responsivo e reativo. Segundo Mizukami (1986, p.35), "As categorias apresentadas colocam em evidência a consideração do homem como produto do meio e reativo a ele". O professor é o elo de ligação entre a ciência e o aluno, é planejador e analista de contingências que projeta e desenvolve no sistema de ensino-aprendizagem.

No paradigma tecnicista, a metodologia promove o envolvimento do aluno, respeitando o ritmo individual de cada um. Através da instrução programada, desenvolve-se uma ação pedagógica que tem em vista a produção de mão-de-obra para a indústria. A escola tem liberdade de programar o ensino das disciplinas, o que garante a aprendizagem. É uma agência educacional e democrática que tem o objetivo de produzir sujeitos competentes.

A avaliação na abordagem tecnicista tem como principal meta a reprodução, exigindo do aluno a memorização e retenção dos conteúdos.

As escolas organizadas de acordo com o modelo tecnicista educavam para atender ao mercado, não contribuindo com o desenvolvimento do indivíduo crítico, comprometido com a transformação social. Reforçavam assim o cultivo de um modelo social conservador, presente ainda hoje em algumas escolas.

\section{PARADIGMAS INOVADORES}

A sociedade atual aponta-nos para a impropriedade de continuarmos atrelados a paradigmas que compreendem o mundo de maneira fragmentada. De acordo com Moraes (1998), os problemas da sociedade atual não são unilaterais, unívocos, têm características trans: transnacionais, transtemáticos, transversais, transdisciplinares... Apontam, pois, para a necessidade do estabelecimento de relações na busca de soluções.

A ausência de relações e conexões nos processos de produção de novos conhecimentos é responsável por 
uma sociedade que está gerando desenvolvimento e expansão de extremos. Como exemplo disso, temos a expansão da tecnologia e também da miséria, extremos que fazem com que a desigualdade social seja agravada pelo processo de exclusão digital.

A fragmentação enraizada no pensamento newtoniano - cartesiano, que separa, entre outras coisas, ética e ciência, tem gerado uma sociedade capaz de realizar grandiosos avanços tecnológicos e científicos, mas que não está preparada eticamente para acompanhar o desenvolvimento complexo da humanidade. Tal fato pode ser comprovado pela utilização indevida da rede de informações (internet) como instrumento de propagação e comunicação para criminosos da pedofilia. Portanto, um dos desafios que temos a enfrentar na passagem da sociedade da reprodução para a sociedade da produção do conhecimento é o seguinte: como desenvolver talentos para a ciência e para a paz?

A educação tem um importante papel nesse processo. O abandono da subjetividade, das emoções, da sensibilidade, a fragmentação das relações humanas, incentivado nos últimos séculos em nome da neutralidade e racionalidade científica, gerou um processo de desumanização da educação. Para Moraes:

Insensível aos valores, o método reducionista foi se enraizando em nossa cultura e levou-nos a um processo de alienação e a uma crise planetária de abrangência multidimensional, traduzidos por processos de fragmentação, atomização e desvinculação. Em conseqüência, a cultura foi ficando dividida, os valores, cada vez mais individualizados, e os estilos de vida, mais patológicos. (1998, p.92)

É necessário que a escola assuma a necessidade de trabalhar com a multidimensionalidade humana, não tratando o aluno como anjo barroco (que só tem cabeça). As dimensões espiritual, psicológica, social, cultural, política e cósmica têm que ser contempladas de maneira sistêmica, explicitando a dinâmica de interdependência presente entre as partes constituintes do educando e todos os demais envolvidos no processo educativo.

A prática pedagógica do século $\mathrm{XXI}$, que atende aos pressupostos da sociedade do conhecimento, é caracterizada por educandos e educadores inter-relacionados, interdependentes em suas atividades, ambos com a função de refletir, defender suas idéias, construir, criticar, produzir e projetar sua existência. Dialética, teoria da incerteza e lei da complementaridade balizam suas ações e relações.

A transposição do paradigma que visava à reprodução do conhecimento para o paradigma da produção do conhecimento, na área da Educação, não pressupõe uma teoria de curva- 
tura da vara, ou seja, superar não significa simplesmente negar. Não pretendemos postular a negação da racionalidade, mas a possibilidade de aliar, de trabalhar de forma sistêmica emoção e racionalidade, entre outras dualidades.

Uma prática educativa atrelada às mudanças paradigmáticas da ciência deve caracterizar-se e constituir-se, como afirma Behrens (2000), na aliança formada entre paradigmas inovadores - a abordagem progressista, a visão holística (que abrange toda uma atitude de vida) e a metodologia do ensino com pesquisa instrumentalizados pela tecnologia também inovadora. Somente a partir da constituição da teia entre essas abordagens é que teremos uma pedagogia capaz de atender aos desafios da sociedade moderna, contribuindo para a construção do conhecimento. Segundo Capra (1996, p.25):

O novo paradigma pode ser chamado de uma visão de mundo holística, que concebe o mundo como um todo integrado, e não como uma coleção de partes dissociadas. Pode também ser denominado visão ecológica, se o termo "ecológica" for empregado num sentido muito mais amplo e mais profundo que o usual. A percepção ecológica profunda reconhece a interdependência fundamental de todos os fenomenos, e o fato de que, enquanto indivíduos $e$ sociedades, estamos todos encaixados nos processos cíclicos da natureza (e, em última análise, somos dependentes desses processo).

No Paradigma Progressista temos uma nova visão em relação aos papéis de professor, aluno e escola. $\mathrm{O}$ aluno é instigado a produzir o conhecimento. É considerado um ser crítico, criativo, sério e principalmente inacabado, ou seja, em permanente construção do saber. Para Freire (1997, p.50): "Aqui chegamos ao ponto de que talvez devêssemos ter partido. $\mathrm{O}$ do inacabamento do ser humano. $\mathrm{Na}$ verdade, o inacabamento de ser ou sua inconclusão é próprio da experiência vital. Onde há vida, há inacabamento."

Nessa perspectiva, além de educador, o professor é também sujeito no processo. É um mediador, líder ético, democrático e autêntico, existindo uma relação horizontal entre ele e o aluno. Já a escola tem um papel de instigar professor e aluno para reflexão num contexto histórico de intervenção para a transformação social.

No Paradigma Holístico a escola visa a aprofundar relações com a comunidade global, com o planeta e com o cosmo. O homem deve recuperar a visão do todo e superar a fragmentação. Principalmente, precisa considerar a intuição, a emoção, a paixão, o amor, o sentimento, com o objetivo de provocar um repensar no universo. São consideradas e estimuladas, 
segundo Gardner (2000), todas as inteligências dos alunos: lingüística, lógica ou matemática, musical, espacial ou visual, sinestésica ou física, interpessoal e intrapessoal. Os alunos são instigados a estimular os dois hemisférios do cérebro. Nesse contexto, o professor tem papel fundamental na superação do paradigma da fragmentação. Ele busca passar da reprodução para a produção do conhecimento.

A abordagem do Ensino com Pesquisa propõe uma formação diferenciada: formar para atender às novas exigências com criatividade, curiosidade, espírito crítico e reflexivo. O profissional deve desenvolver capacidades operativas e estar apto para o uso de novas tecnologias. A escola tem a preocupação em formar o aluno para o exercício da cidadania crítica e o comprometimento com a ética planetária. O aluno é sujeito no processo, questionador, investigador e problematizador. Interage com o professor, o qual tem que instigar o aluno a "aprender a aprender". O professor é orientador e parceiro na formação do educando. Segundo Cunha (1996, p.125):

Recuperar a relação entre ensino e pesquisa é partir do pressuposto de que pelo ensino também se faz produção do conhecimento, incluindo a produção da consciência das novas gerações, fazendo-as sujeitos da própria historia, capazes de enfrentar com independência e cidadania os desafios do mundo tecnológico que se avizinha.

Apontar novos paradigmas para a educação deve significar, necessariamente, novos trajetos na formação de professores, ou todas as proposições feitas cairão na ineficiência e no discurso vazio e superficial. Se o aluno irá percorrer seu processo de formação em um novo contexto, com novas demandas e exigências, os profissionais co-responsáveis pela condução desse processo devem direcionar suas ações para a mesma direção, visando verdadeiramente à efetivação de uma sociedade não reprodutora, mas consciente e autônoma de sua possibilidade criadora.

\section{PARADIGMASDACIÊNCIAE FOR- MAÇÃO DE PROFESSORES}

Historicamente, possuir um certo conhecimento formal era assumir a capacidade de ensiná-lo. Embora não se discuta que essa característica histórica seja necessária, no contexto atual apenas o domínio do conteúdo é insuficiente, uma vez que a profissão docente deixou de ser responsável pela pura transmissão do conhecimento acadêmico, assumindo importante papel na criação de espaços de participação, reflexão e formação dos educandos.

O modelo que marcou toda a nossa formação teve como princípio uma ciência absoluta, verdadei- 
ra, até dogmática, que atualmente, diante de um novo paradigma que se impõe, exige mudanças de natureza epistemológica que interferirão, diretamente, no modo de conceber o ensino e a aprendizagem. Durante toda a nossa formação sempre consideramos o ensino como transmissão de conhecimento, onde o professor tudo sabia e o aluno era uma verdadeira folha em branco a quem competia memorizar e repetir o conhecimento transmitido. (KULLOK, GOMES, 2000, p.23)

O conhecimento do professor não é meramente acadêmico, racional, feito de fatos, noções e teorias, como também não é um conhecimento feito só de experiências. É um saber que consiste em gerir a informação disponível e adequá-la estrategicamente ao contexto. É um saber agir em situação.

Essa nova abordagem exige do educador um re-pensar da prática pedagógica, questionando-se se ela está atingindo todos os seus educandos, se a sua linguagem está adaptada à realidade do aluno. Freire (1997) afirma que ensinar não é transferir conhecimento, mas criar as possibilidades para a sua produção ou sua construção. Nesse processo, o educador é desafiado a perceber sua dimensão dodiscente, pois ao formar, também se forma.

Portanto, o professor precisa conscientizar-se de que está em cons- tante desenvolvimento intelectual e que é isso que vai alimentar a sua prática e dar-lhe suporte para poder acompanhar a evolução tecnológica emergente. Essa conscientização é necessária para que escola e sociedade andem juntas na formação dos profissionais. Segundo Freire, "por isso é que, na formação permanente dos professores, o momento fundamental é o da reflexão crítica sobre a prática. É pensando criticamente a prática de hoje ou de ontem que se pode melhorar a próxima prática" (1997, p.39).

Há urgência em se pensar a formação dos professores como um todo. Um processo atrelado a paradigmas conservadores, voltado apenas à atualização científica, pedagógica e didática do profissional, mostra-se desvinculado e descomprometido com a realidade, gerando o existente descompasso entre a formação e o campo de trabalho.

Faz-se necessário que os cursos de formação de profissionais docentes assumam a aliança dos paradigmas inovadores, caracterizando assim uma nova forma do fazer pedagógico, tomando o conhecimento como fruto de uma elaboração na qual o aprender resulta de um processo de construção. Como afirma Freire, "o homem, como um ser histórico, inserido num permanente movimento de procura, faz e refaz constantemente $o$ seu saber" (1997, p.21).

Para atender às exigências e desafios da sociedade moderna, as práticas de formação de professores de- 
vem gerar reflexão sobre os conteúdos da escolaridade, no sentido de possibilitar a transformação da compreensão sobre o vivido e de oportunizar a construção de conhecimentos significativos, que se reorganizam na relação entre os conceitos cotidianos e científicos. Ao fazer referência à formação de professores, Gadotti afirma: "O educador que se pretende formar para o próximo milênio, deverá ter consciência e atuar em favor de um planeta saudável onde todos possam viver com qualidade e em harmonia universal com todos os seres com os quais compartilhamos a Terra" (2000, p.111).

À luz dos preceitos do paradigma emergente, é imperativo que o professor esteja ciente da função que a educação assume na sociedade atual, onde o conhecimento proporciona ao educando a possibilidade de atuar de forma transformadora sobre a realidade. Isso implica a superação, pelo professor, da compreensão ingênua e historicamente arraigada, de que sua função é simplesmente transmitir conhecimento ao educando. Coerentemente adequada aos paradigmas inovadores, a formação do professor da sociedade atual deve torná-lo capaz de ultrapassar as visões clássicas que o situam no espaço restrito da sala de aula, para reconhecer-se multidimensionalmente como homem/cidadão/ profissional, inserido e em ação na sociedade de seu tempo.

\section{REFERÊNCIAS}

ALARCÃO, I. Formação continuada como instrumento de profissionalização docente. In: PASSOS, I. e VEIGA, A. (orgs.). Caminhos da profissionalização do magistério. Campinas: Papirus, 1998.

ASSMANN, H. Metáforas novas para reencantar a educação. São Paulo: Unimep, 1998.

BEHRENS, M. A. Formação continuada e a prática pedagógica. Curitiba: Champagnat, 1996.

O paradigma emergente e a prática pedagógica. 2 ed. Curitiba: Champagnat, 2000.

. O paradigma emergente e a prática pedagógica. 2 . ed. Curitiba: Champagnat, 2003.

CAPRA, F. A teia da vida: uma nova compreensão científica dos sistemas vivos. São Paulo: Cultrix, 1996.

CARDOSO, C. A canção da inteireza: uma visão holística da educação. São Paulo: Summus, 1995.

CORAZZA, S. M. Educação da diferença, mimeo, 2004.

CUNHA, M. I. da. Relação ensino e pesquisa. São Paulo: Papirus, 1996

. Aula universitária: inovação e pesquisa. In: MOROSINI, M. \& LEITE, D. Universidade futurante. Campinas: Papirus, 1997.

O bom professor e sua

prática. Campinas: Papirus, 1998.

DEMO, P. Educar pela pesquisa. Campinas: Autores Associados, 1996.

FERGUSON, M. Ver e voar: caminhos 
para o aprendizado. In COSTA, E Conspiração aquariana. 7. ed. Rio de Janeiro: Record, 1992.

FREIRE, P. SCHOR, I. Medo e ousadia. São Paulo: Paz e Terra, 1992.

FREIRE, P. Educação e mudança. 27ed, Rio de Janeiro: Paz e Terra, 1979.

Pedagogia da esperança: um reencontro com a pedagogia do oprimido. Rio de Janeiro: Paz e Terra, 1992.

. Pedagogia da autonomia - saberes necessários à prática educativa. São Paulo: Paz e Terra, 1997.

GADOTTI, M. Perspectivas atuais da educação. Porto Alegre: Artmédicas Sul, 2000.

GARDNER, H. Inteligência: um conceito reformulado. São Paulo: Objetiva, 2000.

GOMES, M. e KULLOK, B. As exigências da formação do professor na atualidade. Maceió: Edufal, 2000.

KUHN, T. A estrutura das evoluções científicas. 4. ed. São Paulo: Perspectiva, 1994.

LIBÂNEO, J. C. Democratização da escola pública. São Paulo: Loyola, 1986.

MIZUKAMI, M. Graça N. Ensino: as abordagens do processo. São Paulo: EPU, 1986.

MORAES, M. C. Paradigma educacional emergente. Campinas: Papirus, 1998.

MORIN, E. Os sete saberes necessários à educação do futuro. São Paulo: Cortez, 2000.

NIETSCHE. E. A. Educação em enfermagem: as teorias da educação e o ensino de enfermagem no Brasil. Florianópolis:
Ed. da UFSC. p.125-134, 1998.

NÓVOA, A. (Org.). Profissão professor. Porto: Porto Editora, 1995.

WEIL, P. O novo paradigma holístico. In: BRANDÃO, D. CREMA, R. O novo paradigma holístico. São Paulo: Summus, 1991.

Encaminhado em: 10/08/05

Aceito em: 17/11/05 